\title{
Exploring local risk managers' use of flood hazard maps for risk communication purposes in Baden-Württemberg
}

\author{
S. Kjellgren \\ Department of Social Sciences V, University of Stuttgart, Seidenstr. 36, 70174 Stuttgart, Germany \\ Correspondence to: S. Kjellgren (stina.kjellgren@sowi.uni-stuttgart.de) \\ Received: 26 November 2012 - Published in Nat. Hazards Earth Syst. Sci. Discuss.: - \\ Revised: 24 April 2013 - Accepted: 29 April 2013 - Published: 29 July 2013
}

\begin{abstract}
In response to the EU Floods Directive (2007/60/EC), flood hazard maps are currently produced all over Europe, reflecting a wider shift in focus from "flood protection" to "risk management", for which not only public authorities but also populations at risk are seen as responsible. By providing a visual image of the foreseen consequences of flooding, flood hazard maps can enhance people's knowledge about flood risk, making them more capable of an adequate response. Current literature, however, questions the maps' awareness raising capacity, arguing that their content and design are rarely adjusted to laypeople's needs. This paper wants to complement this perspective with a focus on risk communication by studying how these tools are disseminated and marketed to the public in the first place. Judging from communication theory, simply making hazard maps publicly available is unlikely to lead to attitudinal or behavioral effects, since this typically requires two-way communication and material or symbolic incentives. Consequently, it is relevant to investigate whether and how local risk managers, who are well positioned to interact with the local population, make use of flood hazard maps for risk communication purposes. A qualitative case study of this issue in the German state of Baden-Württemberg suggests that many municipalities lack a clear strategy for using this new information tool for hazard and risk communication. Four barriers in this regard are identified: perceived disinterest/sufficient awareness on behalf of the population at risk; unwillingness to cause worry or distress; lack of skills and resources; and insufficient support. These barriers are important to address - in research as well as in practice - since it is only if flood hazard maps are used to enhance local knowledge resources that they can be expected to contribute to social capacity building.
\end{abstract}

\section{Introduction}

According to the OECD (2003, p. 30), "[t]he impact of natural disasters, especially floods, storms and droughts, has risen steeply since the early 1960s." Statistics by Swiss Re for the period between 1970 and 2011 show that, with few exceptions, each year, natural catastrophes worldwide claimed more victims (dead or missing persons) and resulted in higher insured losses than man-made disasters (Swiss Re, 2012).

Commenting on the developments over the past half century in the field of natural hazards, Weichselgartner and Sendzimir (2004, p. 4) argued that "[t]he paradox of concurrent increases in economic loss and disaster-related research raises questions about the approaches and tools used in hazard assessment and disaster management." In their view, there has been too much focus on nature as a determinant, and too little emphasis of internal factors related to science and policy decisions. Based on a similar analysis, the EU responded to a number of disastrous floods in the 1990s and early 2000s by introducing the EU Floods Directive (2007/60/EC), requiring all Member States to assess the hazard, risk, and need for action to reduce negative impacts from flooding. More concretely, the Directive requires flood hazard maps and flood risk maps to be completed by December 2013, and flood risk management plans to be published by December 2015 .

Flood hazard maps contain information about the extent and depth of inundation associated with different flood scenarios, sometimes together with flow velocity, whereas flood risk maps contain additional information about the expected consequences of these scenarios (e.g. economic damage, number of people affected). In the present paper, flood hazard 
maps are the topic of interest. The reason for this is (a) that the practice of flood hazard mapping is commonly more established than that of flood risk mapping (cf. Seidel and Dorner, 2011), and (b) that previous literature has shown hazard maps to be more useful than risk maps for most target groups (Wagner, 2008).

By visualizing the extent and depth of inundation expected from various flood scenarios, hazard maps provide information that can help risk managers as well as individual citizens anticipate and prepare for flooding (cf. Safer, 2008). The EU Floods Directive, as well as preceding national and regional mapping initiatives, can thus be seen as examples of an interventionist approach to "social capacity building" (Kuhlicke et al., 2011), a top-down attempt to develop and enhance e.g. knowledge resources to help actors at various levels to cope with risk.

At the individual level, social capacity is important for two reasons. First, it can help reduce overall damage potential by making citizens more motivated and capable of protecting themselves and their property (i.e. hazard preparedness). Second, it can help make citizens more apt to participate in the development of locally embedded response strategies (i.e. participation in collective protective actions). This latter point is relevant considering that the Floods Directive encourages the "active involvement of interested parties" in the development of catchment-based flood risk management plans (see Article 10).

A problem with the hazard maps as public information tools is that, when studied in practice, they often do not fulfill their potential to raise awareness (see Sect. 3.1). In recent literature, this has been put down to the maps' design not matching lay-people's needs. Whereas risk managers and other types of experts are able to decode and interpret map content, ordinary citizens find this more challenging, indicating that one size does not fit all (e.g. Hagemeier-Klose and Wagner, 2009; Dransch et al., 2010).

So far, research has tended to focus on the public's awareness (Planat, 2004) or understanding of the maps (Meyer et al., 2012), respectively on the effect of these tools on public risk perception (Handmer, 1980). Little focus has been given to the issue of how these maps are disseminated, explained or marketed to the public in the first place. While flood hazard maps are internationally recognized as "important tools to communicate flood risk to different target groups" (Spachinger et al., 2008, 1), we often remain in the dark as to how this task is approached in practice. Considering that dissemination and communication may influence both people's access to and understanding of the maps, this appears to be a relevant complementary perspective to investigate.

The analysis presented in this paper attempts to address this research gap by exploring local risk managers' perception and use of flood hazard maps as public information tools in the German state of Baden-Württemberg. Hence, although this paper focuses on the role of flood maps as public information tools, it will not target lay-people. Instead, it will focus on the efforts made by decision-makers and administrators at the local level to disseminate and use these tools to draw attention to flood risk. This is a reasonable approach in light of research findings that the largest hurdle on the ladder from knowledge production to knowledge utilization is the step of transmission (Landry et al., 2001).

In the following section, it will be explained how the call for greater citizen participation is part of a new policy approach towards flood risk. In Sect. 3, communication research will be reviewed, which shows that the impact of hazard information is highly dependent on how it is delivered (i.e. as unidirectional information provision or through twoway communication). In Sect. 4, hazard mapping in BadenWürttemberg is reviewed in terms of process and aim. This is followed by an explanation of method, before the results are presented in Sect. 6. The results identify several challenges that risk managers and external observers experience and notice when it comes to the task of risk communication. These challenges are important to study since they can work as barriers towards active efforts to enhance local knowledge about flood risk.

It should be underlined that the aim of this paper is to explore the perception and use of flood hazard maps in a heterogeneous group of risk managers from one particular region for the sake of developing a first, initial understanding of the challenges associated with the implementation of the new approach to risk management, described above. To learn about the significance or applicability of these findings beyond the sample investigated here requires further research. The same goes for questions related to citizens' awareness of the hazard maps and their impact on risk perception.

\section{A new governance approach to natural hazards}

Over the past couple of decades, a paradigm shift has occurred in regard to natural hazards as science and policy have increasingly embraced the social origins of risk, moving away from an analysis of natural disasters as the results of isolated, physical processes. As a result, management strategies based on human control over nature, through technical fixes and "hard science" approaches, have been subject to rethinking, and strategies based on mitigation, resilience and reduction of damage potential have resurfaced (Büchele et al., 2006; Werritty et al., 2009; White et al., 2001). In flood risk management, these developments have followed upon insights as to the risk of dam and dike failure, observation of an "escalator-effect" behind such installations, and doubts about our ability to predict the future based on data from the past (Parker, 1995; Jaeger et al., 2001, p. 95-101).

On the European level, several governments (e.g. in the UK, Germany and the Netherlands) have recognized the limitations of the state's capacity to offer protection from the forces of nature. These governments are now moving away 
from a "safety philosophy", towards a view of risk as something to be "managed", rather than controlled (de Moel et al., 2009; Samuels, 2006). Following the disastrous 2002 Elbe flood, for example, for which the German federal level had to bear much of the cost (Botzen and van der Bergh, 2008, p. 423), the German government quickly released a five-point program to increase cooperation, reduce damage potential and give rivers more space (Bundesregierung, 2002). The EU, similarly, describes floods as natural phenomena that cannot be prevented, calling for maintenance and restoration of floodplains (European Parliament and the Council, 2007).

This shift towards viewing flooding as something natural, which we must learn to live with, also involves a more active role for the public. It has previously been recognized that more "self-protection" on behalf of individuals at risk could reduce the losses from natural hazards significantly (e.g. Grothmann and Reusswig, 2006) and that one of the obstacles in this regard is people's tendency to perceive flood protection as the responsibility of the public authorities (Wachinger et al., 2012). Current European management policy aims to change this, making the populations at risk more responsible for their own safety (Hagemeier-Klose and Wagner, 2009).

While the EU Floods Directive opts for making risk information publicly available and encouraging the active involvement of interested parties in management planning ( $\mathrm{Ar}$ ticle 10), the German federal water law requires citizens at risk to implement mitigation and damage reduction measures in accordance with their possibilities and abilities (WHG, $2009, \S 5,2)$. In both cases, those at risk are "gradually transformed into risk managers and active participants of the multi-scale risk governance network as they are encouraged or even required to take more responsibility for their actions." (Kuhlicke et al., 2011, p. 806). Publication of flood hazard maps can thus be understood both as empowerment, through the provision of transparent risk information, and as shifting responsibility and costs for risk management from a more "hollowed-out" state to more active citizens (cf. TaylorGooby and Zinn, 2006).

According to Steinführer (2009), large parts of the public are not aware of this responsibility shift. Furthermore, they might not be inclined to agree with it. In extension, this means that the official policy may be in dissonance with people's capacity or willingness to become more active and accountable for their own protection. From this perspective, active communication or dialog about risk and responsibility becomes all the more important, as unawareness or opposition could threaten the implementation of the new flood risk management paradigm. Consequently, it is also relevant to ask what responsible authorities do to support and encourage greater citizen participation in the governance of risk, and what role the mandated flood hazard maps play in this regard.

\section{Risk communication}

\subsection{The track-record for hazard maps}

Meyer et al. (2012, p. 1702) have argued that "[i]n practice maps often fail to attain their potential to fulfill the needs of different users, to raise awareness and provide a clear and understandable source of information for planning." As will be seen below, their influence may be compromised in different ways and at different stages along the communication chain.

A first problem is clearly to have them be noticed and considered by a target group in the first place. Though it is difficult in the absence of comparative evidence to tell whether this is high or low, a Swiss survey showed that $75 \%$ of the respondents did not know, or did not think, that flood maps were available for their area (Planat, 2004). A Canadian study, furthermore, found direct dissemination of hazard maps to households to be ineffective in influencing people's risk perception. Although a pre- and post-test survey design did establish a difference in respondents' flood expectation before and after the maps were distributed, there was no significant difference between the group that received maps through direct distribution and the control group. The change in perception was therefore attributed to the intensive media campaign surrounding the maps (Handmer, 1980). Media campaigns are not always effective in this way, however. In one community, Handmer found an almost complete ignorance of the maps' existence only six months after local newspapers covered and even reprinted parts of the maps.

Getting people to notice and consider hazard maps is not the only hurdle, however. Another challenge is to avoid negative reactions. In Handmer's study, not everyone appreciated the arrival of flood maps: "These people, and others in the flood plain, did not regard the maps as a source of information. Instead they saw them solely as part of a program to expropriate their property and as a waste of resources: the money would be better spent on building a dyke." (Handmer, 1980, p. 97). In Bavaria, likewise, hazard zone maps have failed to function as public information tools, inter alia due to conflicts between the local populations and responsible authorities (Wagner, 2006).

While these experiences point to the importance of a reflective and thoughtful communication strategy, maps can still fail to convince people if such a communication strategy is not sensitive to local views and experiences. In the UK, hazard maps were integrated into an active awareness raising campaign implemented by the Environment Agency. Some of the people who were shown in the maps to reside in risk areas rejected this assessment, however, suggesting that the maps were wrong, that the character of their location (e.g. on a hill) disproved a flood risk, or even that the assessment was a form of conspiracy (Burningham et al., 2008). Whereas this shows the importance of trust and credibility in relation to risk communication (cf. Renn, 2008, p. 123ff, 222ff), it is also described by Burningham et al. (2008) to 
illustrate the limits of a communication strategy based on a "deficit-model" of public understanding (cf. Wynne, 1995).

If the development of a communication strategy is left to the local authorities, the result might not be better. In the qualitative part of Handmer's study, there was evidence of uncertainty among community officials "about what to do with the maps" (1980, p. 93), as both officials and local residents were unhappy with the results.

This indicates that it is a true challenge to communicate potentially helpful hazard information to those who might benefit from it. While decision-makers at the local level may be in the best position to do this, due to their closeness to the potentially affected (Greiving et al., 2006, p. 748), they may also have less training and experience in this area than higher level professionals. Potentially, this indicates a need for clear guidelines (or other forms of support) regarding how to pursue flood risk communication and how to use flood hazard maps for this purpose.

\subsection{Lessons from risk communication research}

Intuitively, it is difficult to prepare for a risk that one is unaware of. Therefore, it is vital that documentation and information concerning risks are conveyed to all relevant actors. According to Renn (2008, p. 207), risk communication can enhance people's knowledge about a risk, persuade them to change their attitudes or behavior, promote confidence in the responsible authorities, and provide the conditions for an effective stakeholder involvement in risk issues (also see Wachinger et al., 2012). Risk communication can thus be seen as a key aspect for social capacity building, both in terms of augmenting people's ability and motivation to act and in terms of preparing the ground for participation at the community level (cf. Höppner et al., 2012).

As seen above, however, not all communication strategies are successful. Over time it has been recognized that people's behavior tends to reflect a multitude of factors related to resources, experiences and personal values and assessments, implying that new or additional information may be of limited influence. Furthermore, recipients' understanding of a message is always mediated by existing beliefs, local knowledge and, not least, trust in sources and transmitters. Communication strategies, which regard people's behavior in the face of risk as a mere consequence of an information deficit, are thus problematic (Wynne, 1995).

Generally, one-way communication - that is, transmission of a message from a source to a recipient group without any possibility for feedback - is thought to have a lower chance of impact than two-way communication strategies (Kuhlicke et al., 2011). While printed material or information published online tend to be less time and resource intense than e.g. public meetings, they are also less successful in influencing people's attitudes and behaviors. A two-way communication process is more likely to be effective in this regard, since it gives the audience a chance voice concerns and give feedback. As the roles shift between who communicates and who listens, there is a chance for a mutual learning process (Renn, 2008, p. 201-203, 259-262). From a social capacity building perspective, this implies that those considered as "lacking" in knowledge have a chance to be actively involved in the process of defining their information needs. Apart from the advice to not only focus on one-way strategies, Höppner et al. (2012) draw attention to the importance of integrated longer term campaigns featuring multiple tools.

It should be noted that two-way communication requires willingness on both sides towards listening and respecting different views and perspectives. In practice, a lack of popular interest in a topic can therefore be problematic, as can a poor performance record or unwillingness to adapt to public concerns on behalf of public institutions. Furthermore, some form of benefit or gratification system is sometimes needed to get people to engage in communication.

Though flood maps are often treated as suitable awarenessraising tools, this research review suggests that their influence is likely to depend on the communication strategy pursued. Merely publishing or displaying maps online represent one-way provision of information. To inspire attitudinal and behavioral change, more active efforts on behalf of local authorities may be required. In principle, the Internet could play a part of such a strategy, since forums and chats provide some chances for two-way communication. A quantitative study by Wagner (2004), however, showed Internet to be the least used source of information about natural hazards among the respondents. Thus, it is reasonable to assume that strategies based on personal contact and face-to-face meetings would be preferable communication formats. Currently, however, we know very little about how local authorities approach the task of risk communication.

Finally, it should be noted that communication and participation literature increasingly emphasize that there is no such thing as homogeneous "general public" and that different population groups can require different communication strategies (e.g. Höppner et al., 2010, 2012). Policy documents, likewise, often refer to "interested parties", as opposed to "the public" (see Unnerstall, 2010). This study, however, has deliberately used broad terms like "the public", "local population" and "citizens". The reason for this has its origin in the interview design, which attempted to let the interview partners frame their own images of the public and targeted audiences, and which therefore avoided a pre-formulated classification. Letting the interviewees speak freely was seen as important for getting an unbiased picture of communication as it is pursued in practice. The use of broad terms in this paper thus reflects the limited amount of distinction discerned in the data material (see Sect. 7). 


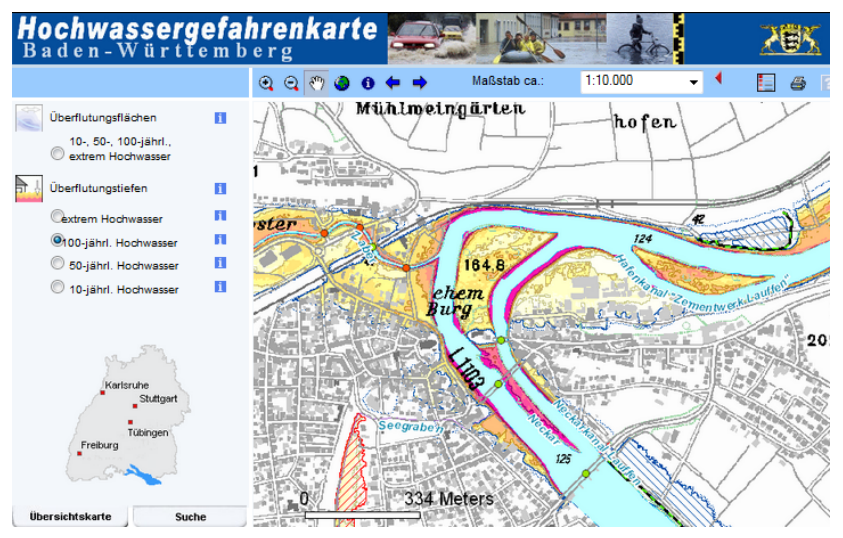

Fig. 1. Flood hazard map depicting inundation depth for the 1/100 years flood scenario. Screenshot from the online map service available from the Ministry of the Environment (http: //rips-dienste.lubw.baden-wuerttemberg.de/rips/hwgk_internet/ \%28S\%28a3fxfb45rlyp0biu4xk2jj55\%29\%29/Default.aspx).

\section{Flood hazard maps in Baden-Württemberg}

\subsection{Maps and mapping process}

In the German state of Baden-Württemberg, the need for flood hazard maps was recognized shortly after the 2002 Elbe floods. It is mentioned as the first of ten items on a list for an integrated action program (reprinted in Ministry of the Environment Baden-Württemberg, 2005). Up until then, only the river Rhine had been systematically mapped, with maps available since 2001 (see IKSR, 2001). Early mapping efforts included calculating the extent of inundation associated with different gauge levels along the Neckar and the Danube rivers (see link list under www.hvz.baden-wuerttemberg.de), as well as the EU-funded Safer project, which mapped flood scenarios associated with different return periods along the Neckar and areas of Scotland and Ireland (Safer, 2008).

Currently, two types of hazard maps are produced for all water bodies with a catchment area larger than $10 \mathrm{~km}^{2}$. The first (see Fig. 1) offers information on the inundation depth, in $50 \mathrm{~cm}$ increments, for the $1 / 100 \mathrm{yr}$ flood scenario. The second type (see Fig. 2) provides information about the expected extent of inundation for a flood with a statistical return period of once in 10,50 and $100 \mathrm{yr}$, as well as for an extreme scenario (e.g. a historic event). Both map types depict flood defenses. Neither of them account for inundation due to groundwater flooding.

The fact that more than $12000 \mathrm{~km}$ of waterways will be covered by maps at a scale of $1: 2500$, suggests that the state attached a high level of importance to hazard mapping even prior to the requirements of the EU Floods Directive. One of the reasons for the meticulous approach might be that the $1 / 10$ and $1 / 100 \mathrm{yr}$ flood scenarios will have legal implication for land-use planning in non-built-up areas (see WG, 2005, §77-78). To the extent that this implies a high level

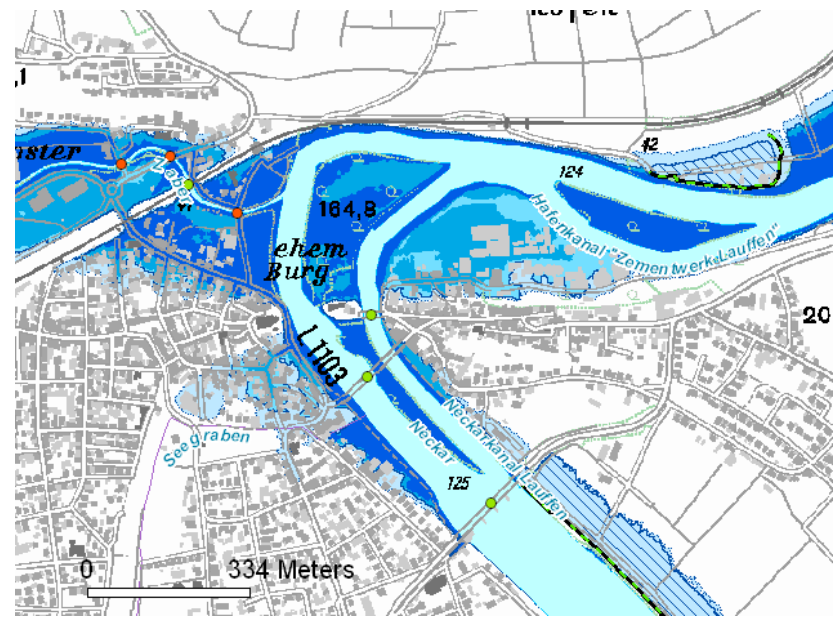

Fig. 2. Flood hazard map depicting expected inundation extent for four different flood scenarios. Graphic from the online map service available from the Ministry of the Environment (http: //rips-dienste.lubw.baden-wuerttemberg.de/rips/hwgk_internet/ \%28S\%28a3fxfb45rlyp0biu4xk2jj55\%29\%29/Default.aspx).

of awareness among local authorities about the maps' existence, it could serve as a "favorable condition" for map usage among local risk managers.

Generally, the mapping process follows a number of recommendations for how to encourage knowledge utilization. Such recommendations include the involvement of intended users throughout the research process and the setting up of institutions or support structures to equip target groups with the willingness and ability to use research (cf. Nutley et al., 2007). In Baden-Württemberg, the map design has been based on consultation with practitioners about their needs and preferences, and local authorities have been able to specify additional catchments (i.e. smaller than $10 \mathrm{~km}^{2}$ ) requiring mapping. During the mapping process, municipalities are furthermore requested to help the responsible engineering bureaus with information, and to review and give feedback on first drafts. Additionally, a training association has been set up to support the formation of voluntary catchmentbased flood partnerships, where municipal decision-makers and administrators can meet and discuss different aspects of risk management.

\subsection{Intended use of hazard maps}

The flood hazard maps are intended to be of use to many actors, including local and regional administrations, insurers, businesses and households. In terms of official risk management tasks, the maps are seen as a suitable tool for spatial planning, emergency management, technical defense planning, and for communication purposes (Ministry of the Environment Baden-Württemberg, 2005). This implies that risk managers have a double role in relation to flood hazard maps. 
Not only are they potential disseminators of these to a wider audience, they are also themselves end users.

Regarding the maps' role as a public information tool, it was suggested in preparation of the Floods Directive that "[p]roducing flood risk maps will mean the public is better informed about flood risks, resulting in increased public awareness" (Commission of the European Communities, 2006, p. 23). In Baden-Württemberg, the flood hazard maps are likewise seen as "an ideal instrument to create awareness", helping stakeholders "see if they are in danger and if precaution activities are necessary" (Safer, 2008, p. 70). The public and business community are specifically referred to as target groups for such instruments (Ministry of the Environment Baden-Württemberg, 2005). Together with supplementary information about how to prepare one's house or business facility for flooding, hazard maps are thus thought to help reduce damage potential by helping people to act in foresight rather than hindsight.

To comply with the requirement to make maps publicly available, a state-wide online map service has been set up (see "Interaktive Gefahrenkarte" under http://www. um.baden-wuerttemberg.de/servlet/is/71525/). Maps are also displayed in paper format at the municipal City Hall and District Administrator's Office (Landratsamt), in accordance with $\S 77$ and $\S 80$ of the Water Law of Baden Württemberg (WG, 2005). Further guidelines regarding dissemination or communication are not provided, although experience shows that authorities at the local level often lack necessary knowhow and manpower to develop independent information campaigns (see Safer, 2008, p. 48).

For this study, the fact that it is up to each local administration to decide upon information campaigns or communication strategies means that even the selection of a small number of municipalities is likely to produce some variation in the approaches opted for. This disparity can be used to uncover central factors affecting different choices. Since the maps are published as they are finished, some municipalities have had access to them for a longer time than others. Indeed, some maps are still under production. Whereas this implies that some administrations may not yet have had the time to initiate information campaigns, it is unlikely to impact on their general reasoning about the prospect of such efforts. An overview of the area for which maps are currently available is offered by Fig. 3.

\section{Method}

Exploring only a limited number of cases, the aim is to make sure that the selection of cases discloses the range of variation and differentiation in the field (Flick, 2009), allowing our understanding of the phenomenon in question to be based on a broad range of circumstances, experiences and perspectives. The results presented in this paper build on 14 semi-structured qualitative interviews with altogether

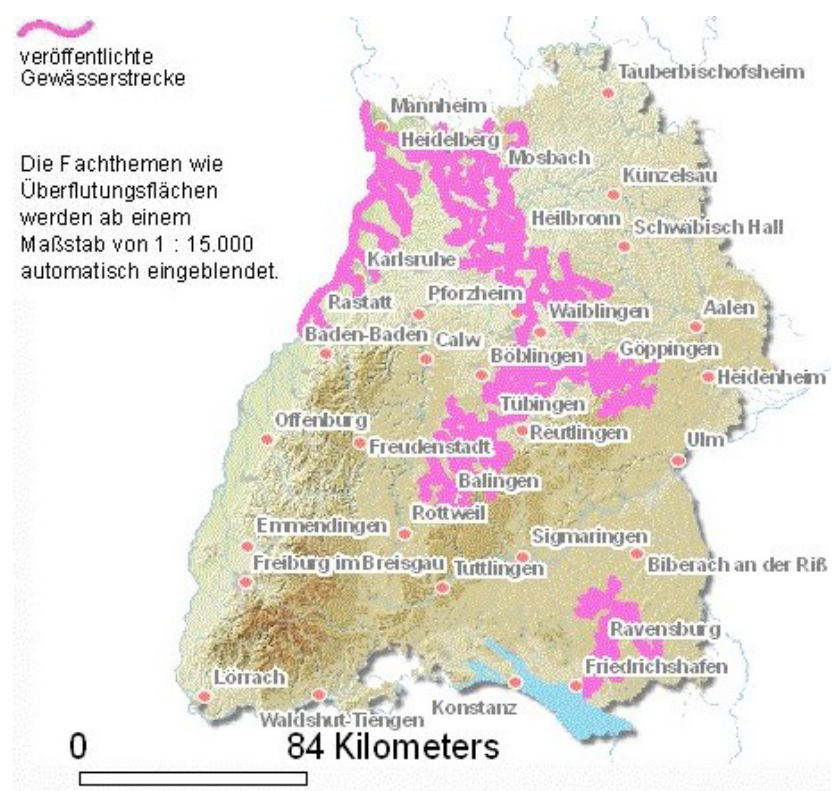

Fig. 3. Overview map of the water stretches in BadenWürttemberg for which flood hazard maps could be viewed in March 2013. Graphic from the online map service available from the Ministry of the Environment (http: //rips-dienste.lubw.baden-wuerttemberg.de/rips/hwgk_internet/ \%28S\%28a3fxfb45rlyp0biu4xk2jj55\%29\%29/Default.aspx).

16 individuals. Eleven of these individuals (interview numbers 1-10) fulfill a risk management function at the local level, i.e. as mayor, emergency manager, spatial planner, or as the responsible party for technical protection or risk management more generally. The municipalities where they work differ in terms of size (from less than 5000 to more than 50000 inhabitants), flood experience (from smaller floods yearly to no flooding for more than two decades), and in terms of whether or not they are members of flood partnerships and associations (i.e. of neighboring municipalities to co-finance structural flood defenses). Geographically, interview partners were selected from within an area stretching from Heidelberg in the north to Albstadt, ca. $80 \mathrm{~km}$ south of the state capital Stuttgart.

The remaining four interviews (numbers 11-14) were held with five experts on the process of introducing the hazard maps as a risk management tools. Since it is always a matter of definition who counts as an expert (Meuser and Nagel, 1991), it should be clarified that these individuals have had unique opportunities to observe this process, either through a position in a public authority or undertaking or through direct involvement in the technical mapping work through a private engineering office. Due to their long experience of observing municipalities' management work, these experts can provide complementary perspectives to those of actors at the local level. These interviews are therefore relevant for uncovering different or complementary explanations for the attitudes and 
behaviors observed at the local level. They may also provide clues as to whether certain such attitudes or behaviors are more or less common. In this sense they serve as a different source of data to be tapped into for corroborating information about the case in question (cf. Yin, 2009). Below, these interviewees will be referred to as "experts" whereas actors at the local level will be referred to as "risk managers".

The interviews lasted between $40 \mathrm{~min}$ and $2.5 \mathrm{~h}$, and covered a broad range of questions pertinent to risk management and flood hazard maps generally. Though many risk managers were not personally responsible for a community's communication strategy, their involvement in the municipal risk management work, and their more or less extensive interaction with private citizens, means that they were all, in principle, in a position to provide insights about the role of the hazard maps in risk communication. The interview transcripts were qualitatively analyzed following the application of a thematic coding approach (cf. Kuckartz and Grunenberg, 2010), in which the software program MAXQDA was used to highlight all references to communication, public relations, etc. All citations included in the results section have been translated from German by the author.

\section{Results}

\subsection{Perceived relevance of maps for encouraging private protection}

One risk manager, working exclusively in the field of emergency management, turned out not to be aware of the maps already available for his area (interview 07). In all other cases, the risk managers were familiar with at least one kind of flood hazard map. Moreover, these maps were clearly perceived as valuable tools for raising awareness about and providing guidance in terms of the local flood risk situation:

I'm an expert when it comes to flood protection and I say: the maps themselves are great. With them you can explain wonderfully. If you use them as a basis and you have people affected by flooding, you can say: "Here, the flood depth is this and that high, and in this area, building is not permissible. And when you want to prevent flooding, or protect yourself against flooding, you have to stack the doors this and that high with sandbags, or whatever." (Risk manager, interview 06)

There you can clearly show people and say: "Here, you're in this area now. If you want to build in a (...), in a built-up area, for example, you can take precaution by considering certain things now already." And you didn't have anything like that before, where it was so clear or as blatant as the maps show it. (Risk manager, interview 04)
This illustrates that the public is indeed perceived to have a role to play in preparing for flood risk and that the flood hazard maps offer helpful information in this regard. Almost every interview offered some comment about citizens' ability to lower damage potential. More precisely, hazard information was seen as relevant for convincing citizens to:

- refrain from building in high risk areas or opt for a suitable design and flood-proof building techniques and materials;

- replace oil-heating systems to reduce the risk of environmental pollution;

- retrofit existing structures, e.g. by installing sewer backflow preventer valves and watertight shields for doors and windows, alternatively having material ready to seal these off;

- be more careful about which goods or appliances are kept in basements, and to have appropriate insurance coverage.

Similar expectations were voiced in the four expert interviews. Additionally, they raise the hope that the maps will make people less inclined to see flood risk as the responsibility of the public authorities, and more as a common responsibility where citizens must also become active agents.

A more detailed understanding of risk is thus thought to empower people to take more responsibility for their own safety, and the maps are broadly regarded as a suitable tool for providing necessary insights to this effect. Apart from the emergency manager in interview 07 , only one other respondent did not mention self-protection as an aim of publishing the maps. For this risk manager, the point of "conveying and sensitizing people to the risk of flooding" was instead to convince them of the necessity of structural defenses:

Because when you come to someone and tell them: "We're building a wall through your garden", even if that wall is just $50 \mathrm{~cm}$ high, they're not going to be thrilled. But if you say you're doing it because you want to protect them, and if you can also support that with a flood hazard map, then they're suddenly open towards such measures. (Risk manager, interview 03)

While this still indicates a view of the maps as a relevant risk communication tool, it also illustrates that the aim of communication is not always to empower people in the face of risk. There is sometimes still a preference at the local level for a more traditional management strategy, based on flood control and emergency services, without a clear role for citizen involvement.

Finally, there is no indication in this sample of local risk managers questioning the hazard maps' ability to convey hazard information to lay-people. Only interviewee 03 expressed any kind of criticism, arguing that statistical return 
periods are technical terms that tell people "nothing", unless they have recently been flooded. Scenarios based on gauge levels were seen as preferable, allowing for an easier comparison with past flood events, thus being easier for people to relate to. Other than this, the respondents did not perceive any problem with the maps themselves, either in terms of content or design.

In principle, then, flood hazard maps are seen as both capable of and relevant for raising public risk awareness. But is their publication sufficient for achieving such an effect in and by itself?

\subsection{Little automatic impact from publication}

Several risk managers observe that the publication and display of the maps online and in city hall has not provoked much response from the public:

To date, no reaction from the public. (Risk manager no. 1, interview 02)

They don't even know about it. They don't realize it. ... In spite of a nice big article in the newspaper as the maps were ceremoniously handed over, with a big event and all that. When a citizen is not directly affected, I don't think it's on their minds. (Risk manager, interview 09)

Neither do they perceive there to have been a change in behavior in the direction of more precaution:

Perhaps in a few years. ... But, so far, I haven't seen that there's any attempt to change anything around here. Rather the opposite is the case: who can still build something quickly, before it's prevented, makes sure to do so. (Risk manager, interview 06)

The lack of public response towards flood hazard maps is also observed by external experts. During the 2002 Elbe flood, at a time when one could reasonably have expected risk information to create quite a stir, recently published hazard maps for the Rhine River were reprinted in color by daily newspapers along the river. Yet there was no noticeable response:

And there was no outcry. ... [M]aybe they took notice of it. But beyond that nothing happened. It also wasn't used somehow politically to say: "So, you've now seen it in the maps, in the Rhine-Atlas. Now we must do something!" (Expert, interview 12)

Many risk managers perceive people to be interested in hazard information only when they are currently thinking about buying property or building a house. Under these circumstances, they may even approach local risk managers for information about the hazard in a specific location. While this is a new trend according to the risk managers in interview 02 , it is not something that they attribute it to the arrival of the hazard maps, but rather to the intense media coverage of the 2002 Elbe and Oder floods and other subsequent events. So, while the maps make it easier for risk managers to provide a clear answer, their publication is not in itself seen to stir up much public reaction. This begs the question what local administrations are doing to draw people's attention to this new tool for learning about flood risk.

\subsection{Type of use made of the maps}

While all risk managers - except the emergency manager of interview 07 - claim to have referred to the flood hazard maps in situations involving contacts with citizens, the type of use most often described is best characterized as "passive". In these cases, information about flooding is provided, but only in response to a citizen making a request or inquiry:

When citizens come and ask.... [T] hey want to rent a flat somewhere or buy a house or so. Maybe there's a plot of land somewhere, where they would like to build. Of those, there is certainly the one or the other who inquires: "Is it a flood plain? When can we expect flooding there? As of what water level?" Every now and then there's the request, and then we refer to the map. (Risk manager, interview 10)

Although such instances are mentioned in almost every interview, the number of people who are confronted with hazard information in this way appears to be modest:

[O]ccasionally, there's the chance to have a look at the flood hazard maps here by us in the city hall. And sporadically, people who are building also come by ... (Risk manager, interview 08, emphasis added)

[W]e get inquiries from people who want to build, and who worry about flooding. But that's only a few. Most people simply start building, without regard for flooding, thinking nothing is going to happen anymore. (Risk manager, interview 06)

Furthermore, this implies that it is only people who have a direct interest in hazard information, and who are already aware of the possibility of an area being at risk of flooding, who actively seek to acquire more knowledge. Those who perhaps falsely - exclude the possibility of flooding, or who prefer to think that they are safe (cf. "ontological safety" in Harries, 2008), are unlikely to be reached under this type of passive communication strategy. While some details might spread by word-of-mouth, this is not something that the respondents mention that they expect or rely on.

According to one of the experts, it is not unusual that municipalities without recent flood experience fail to transmit 
flood risk information to the public. According to him, there are "only a few exceptions there" (interview 12). This includes the flood hazard maps, which, unless they are bound into some sort of sensible public relations work, "generally don't have much impact" (Expert, interview 12). One risk manager was clearly frustrated by what he saw as underuse of a good communication tool among many municipalities:

For someone who's familiar with the flood problematic, it's a blessing, the flood hazard maps. But they must be better conveyed to the population. ... It's really a question of what you do with them. At the moment they're just standing there on the Internet, waiting to be used. (Risk manager, interview 06)

Though "passive" use of the maps was most commonly referred to, in a couple of cases (both in areas flooded within the last five years), active communication efforts were pursued, aimed at reaching a wider audience. This involved organizing public meetings where the hazard maps were presented and explained, sometimes together with specific information about insurance aspects and easy-to-do measures to protect one's home and property. Plans for a similar undertaking were also underway in a community only recently provided with hazard maps, which had not been seriously flooded for the last $20 \mathrm{yr}$.

Though public meetings were held in a couple of cases, the experiences of these events seem to be mixed, with one mayor describing it as "a rather short and somewhat politically motivated affair" (interview 01 ). Two problems encountered were (a) a low level of public interest in such meetings, unless an area has been recently flooded, and (b) that people's interest stems as much from anxiety about losing opportunities, e.g. in terms of construction and development, as from worry about flood risk. As the quote below shows, risk is sometimes seen as secondary compared to free disposal of one's property:

[T]hese people, well they had a look at [the map] then, but they were of the opinion that for them the important thing was to not be confined. This was their property, their land, and they wanted to be able to proceed pretty much like before. (Risk manager, interview 01)

Under such circumstances, presentation of flood hazard maps does not necessarily serve to raise residents' risk awareness, as people may instead focus on what they see as unwelcome implications in terms of land-use restrictions.

Another kind of active communication effort, though at a smaller scale, was when risk managers took the initiative to meet with individual citizens or households. This was described to happen when an administration wanted or needed something that they could only get through persuasion, such as convincing someone not to build in a flood risk area (i.e. where this could not be formally prohibited), or to convince someone to accept an engineering solution (e.g. dikes) even when this would have negative effects on their property. In these situations, the hazard maps were strategically used to convey the presence or severity of a risk, or to illustrate the basis for the administration's plans or viewpoints.

While these face-to-face meetings were often described as successful, risk managers sometimes seem to value photos higher than hazard maps when it comes to convincing people of a flood risk:

[W]hat's really impressive is when we show photos from previous flood events. Then no one can say "I don't see it. I don't want to see it." (Risk manager no.2, interview 02 )

One reason for this may be that photos are less easily questioned compared to the maps. One reaction to the hazard maps was otherwise for critical individuals to challenge the credibility of the $1 / 100 \mathrm{yr}$ flood scenario (Risk manager, interview 03).

To summarize, this suggests that, although some two-way communication occurred on the basis of the maps, this was most likely when the aim was to convince individual residents of official plans or positions. In other cases, there was often no coherent strategy for encouraging people to take notice of the flood hazard maps. Considering that many risk managers seem to recognize that publication and display alone are not succeeding in catching people's attention, one might wonder how come a more comprehensive communication strategy is not pursued.

\subsection{Why so little risk communication?}

In light of recent criticism of current map designs in academic literature (e.g. Dransch et al., 2010), it is worth noting that the lack of active dissemination effort was never attributed, by any of the interviewees, to dissatisfaction with the quality, content or format of the maps. Whereas optimization might still be necessary to make designs more intuitive to lay-people, the findings of this paper suggest that an additional reason for why maps do not always have much impact on people's attitudes and behaviors (see Sect. 3.1), might be the low level of active efforts to promote and disseminate these tools to local populations. At least in the sample investigated here, there was often a preference for a more passive stance towards risk communication. A few factors help us understand why this was the case.

\subsubsection{Factor 1: perceived disinterest/sufficient awareness}

First, some interviewees were of the impression that people are not interested in hearing about or discussing flood risk. Sometimes this was attributed to a natural human tendency to repress bad memories or knowledge of the possibility of negative impacts. Such findings have been reported in 
psychological and cognitive research about risk perception, showing that people use heuristics and biases when assessing risks (e.g. Kahneman and Tversky, 1974). In the present material, risk managers' impression was that, unless people are themselves directly affected, e.g. in the sense of looking to move, build or buy property, or in the sense of recent negative experiences, people are not interested in learning about risk. In extension, this seemed to lower the motivation of some managers, implicitly implying that there was "little use" in seeking to draw attention to flood hazard information.

I think the citizen is not interested. Unless now they are personally affected, because they want to buy a house or a piece of land. (Risk manager no. 2 , interview 02)

Alternatively, it was argued that people are already sufficiently aware about the flood risk in their area. There is no need to "tell" them, since more information does not do anything to change their situation. Referring to residents in a flood-prone area, one risk manager stated that "[n]othing changes for them", then adding:

They know exactly how high the water stood in the basement at this and that time. At the most they would start discussing, saying "that's not correct". (Risk manager, interview 09).

In other words, the maps are not thought to be of any benefit to people who have already experienced flooding. They might even be questioned or rejected. Consequently, there is also no use in disseminating them actively. This view was also present in interview 05 :

I don't really see the necessity for that. Especially since the affectedness is limited to a few residential houses and a couple, or probably only a single store. They know the fact of the matter, because they've already experienced it. .... Insofar, there's also no reason to raise panic. (Risk manager, interview 05)

Independently of whether the public is thought to be disinterested or already sufficiently well informed, the conclusion for many risk managers seems to be that little can be gained by using the hazard maps for risk communication. This can be contrasted against research showing that preparedness levels disintegrate in periods of calm, and that behavioral change requires continuous transmission of the same information also after reaching awareness (e.g. Renn, 2008, p. 239). Moreover, this view fails to account for newer residents who have yet to experience flooding or for the possibility of the next inundation surpassing human memory. Though a perception of disinterest is a serious challenge to any communication effort, it also alerts us to the importance of supporting municipalities with a better understanding for why communication matters and how it can be done to draw people in.

\subsubsection{Factor 2: unwillingness to cause worry or discontentment}

A second factor that seems to affect decision-makers' willingness to communicate is the fear of stirring up public worry and unrest. One risk manager openly suggests that:

$[\mathrm{N}]$ aturally, you don't market something negative ... That could give people the idea that they might not be perfectly protected. Therefore, in this area that has political reasons - we only communicate positive news ... (Risk manager, interview 08)

While this risk manager finds the maps helpful for aspects of his own work, the fact that they depict a risk that the administration currently lacks the funds to address disqualifies them for wider dissemination. Whereas many would argue that the very point of hazard maps is to convey the existence of a threat to people to enable them to make their own decisions and preparations, this is apparently not how interviewee 08 sees matters.

A variation on this theme is the suggestion that it is not meaningful to communicate before progress can be demonstrated, since this would only upset and worry people unnecessarily:

For us, it's currently more important to establish the structural defense than to invest the time and to prepare material to inform the public, only to have to say: "We must still do this and that." It's perhaps more meaningful to make a start first, saying: "We're building. We're doing it." And then inform parallel. Because otherwise it kind of has the effect of making citizens afraid and an extreme pressure building up. (Risk manager no. 2, interview 02)

Many communities - both large and small, recently and not-so-recently flooded - still seem to regard structural defenses and technical solutions (e.g. wider drainage pipes) as the main solution to flood risk. To tell people that there is no money, or that an engineering solution has yet to be initiated, is, in this context, seen as something that can reflect badly on the administration or have political consequences. Therefore, although it is desired that people undertake more self-protection, the information that could inspire them to do so is sometimes not openly communicated for fear that it will backfire as public discontentment.

Experts agree that it is a general problem that public service providers, faced with limited resources and piling demands, do not want to "scare" the population. In practice, however, the consequence of such attitudes is that the impression of flood risk as the responsibility of the public authorities, and as something that the citizens should not have to worry about, remains in place. While some respondents (commonly experts and risk managers working in areas where walls or embankments are not possible for topographic reasons) attest to the possibility of pursuing a management 
strategy based on non-structural solutions, the support of the local population for this is seen to require an open and transparent display of facts, as well as a keen ear for citizens' sorrows and viewpoints.

Concern about negative effects on property values and insurance premiums might further deter communication efforts. While the population is expected to tolerate some consequences of this type, a couple of interviewees see a limit to the losses that individuals should have to bear. For example, there is worry about having to "disinherit" people by revoking building rights on plots of land, for which people might have paid taxes for years already - all due to a calculation, which is to be redone in a few years' time. Some dissatisfaction was shown about higher authorities not having considered how to handle such complications.

Administrations' deliberations about whether to arrange information evenings about the maps for the public are not unaffected by these types of concerns:

[A]t the moment it's rather the danger that something will be set off here that's being perceived. ... That we will be overwhelmed with inquiries and actually we're not even the ones who initiated this whole thing. So, it's being seen a bit ambivalently.

Will there be a storm of protest, because many will see "oh, I'm in a flood plain", which they might not have known before? And whether some of that will befall us.... (Risk manager, interview 04)

Such worries could in the worst case prevent transparent risk communication.

\subsubsection{Factor 3: lack of skills and resources}

This brings us to the third aspect potentially impeding communication, namely a lack of various forms of skills, expertise and resources at the municipal level. As one interviewee puts it:

You need special knowledge about flood protection in order to make it appealing to the citizens. Where the positive aim lies; the virtue of the flood hazard maps. And that's not being communicated by the municipality. Also because the personnel is not there and the technical knowledge not there. (Risk manager, interview 06)

Whereas a lack of personnel with the right set of competences is especially likely in small communities with few employees, it is also brought up as a hindrance by interviewees in larger municipalities (>50 000 inhabitants).

Sometimes, those finally responsible for flood risk management lack expertise in this field. In these cases, local decision-makers may themselves need to be persuaded of the purpose and benefit of hazard mapping:
Quite some persuasion work is still needed, to make sure that the personnel working in City Hall, for example, or in various places at the District Administrator's Office, that they are also convinced that the maps bring a blessing for people. It always resonates like: "Oh, those flood hazard maps, they just cause trouble.” (Risk manager, interview 06)

The need to communicate the virtue of the maps in an "extremely forward" way thus applies to local politicians as well as to the general public (Risk manager, interview 01).

\subsubsection{Factor 4: insufficient support}

Finally, the underuse of flood hazard maps is sometimes partially blamed on the state. Unwilling municipalities are "let off the hook" by the fact that there is no implementation strategy for conveying the maps to the citizens. Recent organizational reforms are described as having dispersed the responsibility for water management issues, leaving no one in charge. Though voluntary flood partnerships facilitate intermunicipal exchange, they are only for officials and not for the public, and therefore not seen to be the right forum for public outreach.

Some external experts agree with the assessment that municipalities require more support, mentioning the possibility of templates for printed information material and webpages. There is some doubt, however, about the extent to which municipalities would actually make use of such templates, were they to be developed (interview 11). Furthermore, there is some uncertainty even at higher administrative levels in terms of how best to communicate the flood hazard maps to "ordinary" citizens:

[I]f you're providing this information to the municipalities, it's still ok, since there's also some kind of contact person at the same level, so to say. They know what modeling is, and know how this has come into being. But if you transport it to the public, to the private man, then it becomes really difficult. And there we have often asked ourselves, how we can best do this. (Expert, interview 13)

Even those who are experts in relation to flood processes and technical management issues, then, can feel uncertain about their competence when it comes to the issue of communication.

\subsection{Perceived benefits from hazard maps}

All in all, the sample offers little evidence of widespread or systematic use of the flood hazard maps at the local level for pursuing a comprehensive, multiple-tool based communication strategy. Furthermore, the public is not perceived to have noticed or responded to the maps' publication to any significant degree. Does this mean that risk managers are discontent with the maps? On the contrary, there are clear indications of 
satisfaction with the role and impact of the maps in relation to the local population, for example when it comes to the possibility of illustrating the risk of flooding:

In the past, when we were planning structural protection works in one or another location, we were reproached: "There has never been a flood..." And that is the main problem. Today, because of the technical possibilities, I can simulate or calculate where I have a risk of flooding. Also when in the last 50 or 100 years there wasn't any flood. (Risk manager no. 1 , interview 02 )

As illustrated by this quote, the maps can help risk managers support their knowledge claims and give weight to their arguments. This can be compared to previous documentation, which was often dismissed by the public as "outdated" (Risk manager, interview 01). Previous documentation was furthermore often fragmentary. In relation to attempts to designate floodplains this caused "massive problems" (Risk manager, interview 05) as local farmers and affected residents questioned the scientific basis, arguing that their area had not been flooded within living memory. The flood hazard maps are perceived to avert such problems:

But now that it's possible to calculate this on the basis of a topographic terrain model ... then it's not really so easy to challenge anymore. And then it's de facto (...) flood plain. Whether the residents are of the opinion that it's lawful or technically justified or not doesn't matter. (Risk manager, interview 05)

The new hazard maps are thus partially appreciated because, building on a more solid process and having certain legal implications, they reduce the potential for conflict, undercutting the arguments for local opposition.

In fact, some risk managers and experts, both, are disturbed by what they see as a rising trend of public protest against flood protection projects - also when these are "for the common good" (Expert, interview 14). Increasingly, such projects are delayed or even stopped, and sometimes the means for achieving this is through a participatory process. Where this trend comes from is not clear to the interviewees. Neither is it obvious how best to respond: by soul-searching, earlier and more elaborate communication, or by requiring more backing from the state?

In effect, this means that practitioners sometimes have a very different impression of what it means to engage in public participation, compared to the picture found in research and policy documents. These concerns must be taken seriously. Academic literature recognizes that, if done improperly, deliberation can "lead to inefficiencies, stabilize existing power distributions, and make ignorance and incompetence the guiding principles for decision-making" (Renn, 2008, p. 283). If more active involvement of citizens is to be encouraged, practitioners may require both a better theoretical understanding of participation and more practical support in terms of how to pursue such processes.

To summarize, it would seem that the welcoming of the maps at the local level is not always related only to their potential as a public risk communication tool. Sometimes, what is also appreciated is their capacity to illustrate a risk for the sake of legitimizing management measures, which might otherwise be subject to protest and conflict.

\section{Discussion}

Flood hazard maps can be regarded as suitable tools for social capacity building both for the sake of encouraging more self-protection and stakeholder involvement in management decisions. Among the respondents interviewed in Baden-Württemberg, there is broad agreement that flood hazard maps are relevant tools for encouraging people to become more active in the face of risk. Invariably, however, their expectations concern activities in the private realm, related to housing and property. Dialog or involvement at the community level is not mentioned. In fact, higher-level engagement often seems to be associated with protests and "difficult demands" - whether it is about people refuting structural defenses or pushing for them - making it questionable to what extent local decision-makers actually welcome the idea of more citizen participation. In effect, this suggests that, although it is depicted as problematic if people rely too much on public authorities to protect them, little is done to change this by opening up a discussion with the population about management and responsibility.

For the flood hazard maps, this means that, sometimes, instead of being used as a basis for discussion, they are strategically used to support authorities' pre-formulated plans and strategies. While this involves conveying flood risk information, thus potentially raising awareness, it may also serve to undercut discussion. In these instances, the maps serve the latent function of making it more difficult for people to question the official interpretation of risk and required measures. It is questionable whether this type of use increases anyone's autonomy and agency to deal with risk, except possibly the involved authorities'.

Although it is seen as desirable that people become more responsible for their own safety, there is rarely a clear strategy for drawing attention to hazard information in the sample investigated. In spite of identifying flood hazard maps as appropriate awareness-raising tools, many of the interviewed risk managers rely on passive strategies for information dissemination and risk communication, relying on citizens' inclination to request information. Furthermore, interviewees rarely distinguished between different population groups. The main exceptions in this regard were risk manager 03's differentiation between people at risk of flooding and those affected negatively by flood defenses construction (the latter group being seen as more "unavoidable" to reach 
out to), and mentioning in interview 11 of a best practice example where separate information meetings about protection strategies were held for local businesses and citizens. This is noteworthy since it may affect the effectiveness of communication strategies if people are treated as a homogeneous crowd.

The research presented here has identified four factors as potentially relevant for understanding risk managers' reliance on passive strategies:

- a low appraisal of the public's interest in communication, implying a low expectation of what it would bring to try;

- a fear of triggering a negative reaction (e.g. public worry or dissatisfaction);

- a perceived lack of necessary resources, like skills and expertise, for being able to communicate successfully; and

- a lack of pressure from the state together with a lack of support (e.g. in the form of best-practice examples, templates or training).

Providing that publication and display alone might not be the best strategy for reaching people at risk, these obstacles pose a serious challenge for the prospect of flood hazard maps contributing to the enhancement of public risk awareness. To the extent that these factors reflect a lack of confidence or experience among risk managers, targeted attempts could be undertaken to enhance their "communicative capacity". This could involve tactics and information about how to handle and respond to public discontent and concern, as well as practical guidelines for format and presentation of a message. It could also be investigated whether, perhaps, the fear of public uproar is exaggerated, respectively how citizens' motivation to engage in two-way communication can be raised.

To some degree, however, the problem also seems to be that practitioners lack motivation or a clear understanding for why they should disseminate flood hazard information. There might even be an unwillingness to do so, since this could disturb the picture of flood risk as something that the local administration is in control of - a picture that both citizens and risk managers have gotten used to. Whereas some practitioners detect a change in the public climate in terms of a higher readiness to question political risk decisions, they lack a clear understanding of what a new model for public relations might entail and require. This, in turn, constitutes a more serious challenge, since it raises doubts about the current foundation for the implementation of a new risk management approach.

Finally, it is noticeable that examples of (or plans for) active communication efforts, respectively absence thereof, were present in both smaller and larger municipalities, as well as for ones with more recent, respectively distant, flood experience (although experience was mentioned by experts as an influential factor). Though the experts generally had less to say about communication, nothing suggests that their observations contradict those of the risk managers analyzed here.

\section{Conclusions}

Implementation of a new approach to flood risk management, focused more on non-structural alleviation and risk mitigation and less on flood control, is likely to require the support of the local population for at least two reasons. First, public opposition is a challenge to any policy shift; rendering implementation more difficult or (politically) costly, thereby potentially undermining decision-makers' motivation. Second, the new management approach expects people to take more responsibility for their own protection and vulnerability, thus implicitly requiring them to accept the "rolling back" of the state's ability or willingness to guarantee their safety. Risk communication and public discussion about different management options can play an important role in this regard, both by increasing understanding for risk management as a shared responsibility and by building social capacity to respond to risk. Research has shown that especially participatory exercises can motivate personal action and reduce people's focus on technical measures (see Wachinger et al., 2012).

Flood hazard maps can constitute a powerful tool when it comes to risk communication and management dialog. Not only can they enhance recipients' knowledge resources, thereby facilitating informed discussion as well as raising capacity for more private protection. They can also provide a common visual basis for a two-way exchange about the local risk situation.

The focus in this paper has been on the issue of whether and how local authorities take advantage of this new tool in their contacts with members or groups of the general public. The results have offered little evidence of widespread or systematic use of flood hazard maps at the local level in the investigated region, for either public information or risk communication purposes. Though this paper is based on a case study and a limited number of interviews, it can be noted that research undertaken in Bavaria, likewise, found it unlikely that active communication efforts were pursued on the basis of available floodplain maps (Wagner, 2006). Moreover, a review of 60 communication practices across Europe showed that risk maps were "not necessarily well advertised amongst the public through additional information materials or events." (Höppner et al., 2012, p. 1767). This implies a more general need for research and practical support to encourage dissemination and risk communication, since even the best information sources can go unnoticed in the absence of efforts to draw attention to them. 
Previous research has identified a number of barriers to flood hazard maps as tools for risk communication, dealing with how these are understood and evaluated by various recipients (Pardoe et al., 2011). The present paper has complemented these findings by focusing on barriers towards dissemination and communication, arguing that these barriers can prevent the maps from reaching a wider audience in the first place. The findings suggest that local-level risk managers may not yet have the understanding or "communicative capacity" required for these tools to be purposefully applied for enhancing local knowledge resources, and thus to contribute to social capacity building. By not wanting to disseminate hazard information unless/until protective measures are underway, for example, local administrations uphold the image of flood safety as the responsibility of public authorities, thereby undermining the need or motivation for citizens to prepare for risk.

Steinführer (2009) previously noted that participation research and policy all too often tacitly assume that people want to be involved in decision-making processes concerning flood risk. Based on the findings of this paper, one might also question the extent to which implementing authorities are currently capable and willing of pursuing a participatory decision-making model, or otherwise share the responsibility for flood risk management. This aspect is important since it draws attention to the gap between the extent to which research and policy expect citizens to be active, and the extent to which opportunities and activities within and beyond the private realm are encouraged in practice.

In conclusion, the present paper illustrates a need to not only study the populations at risk, but also the local-level risk managers most likely to influence public attitudes and behaviors. Particularly, there is a need to focus more on how to encourage and support local administrations to pursue risk communication, especially of the two-way kind, to increase the chances of available flood hazard information reaching those who could benefit from it.

Acknowledgements. This work was supported by the German Research Foundation (DFG) within the funding program Open Access Publishing. The author wishes to thank the editor and reviewers for their constructive feedback and comments.

Edited by: C. Kuhlicke

Reviewed by: two anonymous referees

\section{References}

Botzen, W. J. W. and van den Bergh, J. C. J. M.: Insurance against climate change and flooding in the Netherlands: present, future, and comparison with other countries, Risk Anal., 28, 413-426, doi: 10.1111/j.1539-6924.2008.01035.x, 2008.

Büchele, B., Kreibich, H., Kron, A., Thieken, A., Ihringer, J., Oberle, P., Merz, B., and Nestmann, F.: Flood-risk mapping: contributions towards an enhanced assessment of extreme events and associated risks, Nat. Hazards Earth Syst. Sci., 6, 485-503, doi:10.5194/nhess-6-485-2006, 2006.

Bundesregierung: 5-Punkte-Programm der Bundesregierung: Arbeitsschritte zur Verbesserung des vorbeugenden Hochwasserschutzes, available at: http://www.umweltdaten.de/rup/ 5-punkte-programm.pdf (last access: 20 March 2013), 2002.

Burningham, K., Fielding, J., and Thrush, D.: "It'll never happen to me": understanding public awareness of local flood risk, Disasters, 32, 216-238, doi:10.1111/j.1467-7717.2007.01036.x, 2008.

Commission of the European Communities: Commission Staff Working Document: Annex to the Proposal for a Directive of the European Parliament and of the Council on the assessment and management of floods, SEC(2006)66, available at: http://ec.europa.eu/environment/water/flood_risk/ pdf/sec2006_66_en.pdf (last access: 16 August 2010), 2006.

de Moel, H., van Alphen, J., and Aerts, J. C. J. H.: Flood maps in Europe - methods, availability and use, Nat. Hazards Earth Syst. Sci., 9, 289-301, doi:10.5194/nhess-9-289-2009, 2009.

Dransch, D., Rotzoll, H., and Poser, K.: The contribution of maps to the challenges of risk communication to the public, Int. J. Digital Earth, 3, 292-311, doi:10.1080/17538941003774668, 2010.

European Parliament and the Council: Directive 2007/60/EC of the European Parliament and of the Council of 23 October 2007 on the assessment and management of flood risks, Vol. L288 of the Official Journal of the European Union, 2007.

Flick, U.: An introduction to qualitative research, 4th Edn., Sage Publications, London, 2009.

Greiving, S., Fleischhauer, M., and Wanczura, S.: Management of natural hazards in Europe: the role of spatial planning in selected EU member states, J. Environ. Plan. Man., 49, 739-757, doi:10.1080/09640560600850044, 2006.

Grothmann, T. and Reusswig, F.: People at risk of flooding: why some residents take precautionary action while others do not, Nat. Hazards, 38, 101-120, doi:10.1007/s11069-005-8604-6, 2006.

Hagemeier-Klose, M. and Wagner, K.: Evaluation of flood hazard maps in print and web mapping services as information tools in flood risk communication, Nat. Hazards Earth Syst. Sci., 9, 563574, doi:10.5194/nhess-9-563-2009, 2009.

Handmer, J. W.: Flood hazard maps as public information: an assessment within the context of the Canadian flood damage reduction program, Can. Water Resour. J., 5, 82-110, 1980.

Harries, T.: Feeling secure or being secure? Why it can seem better not to protect yourself against natural hazards, Health Risk Soc., 10, 479-490, doi:10.1080/13698570802381162, 2008.

Höppner, C., Bründl, M., and Buchecker, M.: Risk communication and natural hazards, CapHaz-Net WP5 Report, Swiss Federal Research Institute WSL, available at: http://caphaznet.org/ outcomes-results/CapHaz-Net_WP5_Risk-Communication.pdf (last access: 18 October 2011), 2010.

Höppner, C., Whittle, R., Bründl, M., and Buchecker, M.: Linking social capacities and risk communication in Europe: a gap between theory and practice?, Nat. Hazards, 64, 1753-1778, 2012.

IKSR: Atlas der Überschwemmungsgefährdung und möglichen Schäden bei Extremhochwasser am Rhein: Atlas 2001, IKSR, Koblenz, available at: http://www.iksr.org/fileadmin/user_ upload/Dokumente_de/Rhein-Atlas/atlas/map_overview.pdf (last access: 12 April 2012), 2001. 
Jaeger, C. C., Renn, O., Rosa, E. A., and Webler, T.: Risk, uncertainty, and rational action, Earthscan, London 2001.

Kahneman, D. and Tversky, A.: Judgement under uncertainty: heuristics and biases, Science, 185, 1124-1131, 1974.

Kuckartz, U. and Grunenberg, H.: Qualitative Daten computergestuitzt auswerten: Methoden, Techniken, Software, in: Handbuch qualitative Forschungsmethoden in der Erziehungswissenschaft, edited by: Boller, H.; Friebertshäuser, B., and Richter, S., Weinheim [u.a.], Juventa-Verlag, 501-514, 2010.

Kuhlicke, C., Steinführer, A., Begg, C., Bianchizza, C., Bründl, M., Buchecker, M., De Marchi, B., Di Masso Tarditti, M., Höppner, C., Komac, B., Lemkowe, L., Luther, J., McCarthy, S., Pellizzoni, L., Renn, O., Scolobig, A., Supramaniam, M., Tapsell, S., Wachinger, G., Walker, G., Whittle, R., Zorn, M., and Faulkner, H.: Perspectives on social capacity building for natural hazards: outlining an emerging field of research and practice in Europe, Environ. Sci. Policy, 14, 804-814, doi:10.1016/j.envsci.2011.05.001, 2011.

Landry, R., Amara, N., and Lamari, M.: Climbing the ladder of research utilization: evidence from social science research, Sci. Commun., 4, 396-422, 2001.

Meuser, M. and Nagel, U.: ExpertInneninterviews - vielfach erprobt, wenig bedacht, Ein Beitrag zur qualitativen Methodendiskussion, in: Qualitativ-empirische Sozialforschung. Konzepte, Methoden, Analysen, edited by: Garz, D. and Kraimer, K., Westdeutscher Verlag, Opladen, 441-471, 1991.

Meyer, V., Kuhlicke, C., Luther, J., Fuchs, S., Priest, S., Dorner, W., Serrhini, K., Pardoe, J., McCarthy, S., Seidel, J., Palka, G., Unnerstall, H., Viavattene, C., and Scheuer, S.: Recommendations for the user-specific enhancement of flood maps, Nat. Hazards Earth Syst. Sci., 12, 1701-1716, doi:10.5194/nhess-121701-2012, 2012.

Ministry of the Environment Baden-Württemberg, Flood risk maps in Baden-Württemberg - guidelines, available at: http://www.hochwasser.badenwuerttemberg.de/servlet/is/1253/ HWGK_Leitfaden_ENG.pdf (last access: 18 May 2010), 2005.

Nutley, S. M., Walter, I., and Davies, H. T. O.: Using evidence, How research can inform public services, Policy Press, Bristol, 2007.

OECD: Emerging systemic risks in the 21st century: an agenda for action, Final report to the OECD futures project, OECD, Paris, available at: http://www.oecd.org/futures/globalprospects/ 37944611.pdf (last access: 31 March 2010), 2003.

Pardoe, J., Priest, S., Kuhlicke, C., and McCarthy, S.: Findings from participation in all case studies (including an overview of participants), in: RISK MAP - Improving flood risk maps as a means to foster public participation and raising flood risk awareness: toward flood resilient communities, edited by: Meyer, V., Kuhlicke, C., Luther, J., Unnerstall, H., Fuchs, S., Priest, S., Pardoe, J., McCarthy, S., Dorner, W., Seidel, J., Serrhini, K., and Palka, G., 247-266, available at: http://risk-map.org/outcomes (last access: 2 March 2013), 2011.

Parker, D.: Floodplain development policy in England and Wales, Appl. Geogr., 15, 341-363, 1995.

Planat: Hochwassergefahren in der Schweiz: Risikobewusstsein in der Bevölkerung und die Implikationen für eine erfolgreiche Risikokommunikation, Planat, c/o Bundesamt für Wasser und Geologie, Biel available at: http://www.planat.ch/fileadmin/ PLANAT/planat_pdf/alle/R0483d.pdf (last access: 2 July 2012), 2004.
Renn, O.: Risk governance: coping with uncertainty in a complex world, Earthscan, London, 2008.

Safer: Strategies and actions for flood emergency risk management: experiences and recommendations of the SAFER project, Stuttgart, available at: http://www.eu-safer.de/fileadmin/ user_upload/files_public_area/Results/SAFER_Joint_Report.pdf (last access: 15 June 2010), 2008.

Samuels, P. G.: A European perspective on current challenges in the analysis of inland flood risks, in: Flood risk management: hazards, vulnerability and mitigation measures, edited by: Schanze, J., Zeman, E., and Marsalek, J., Springer, Dordrecht, 21-34, 2006.

Seidel, J. and Dorner, W.: Current practices of flood mapping in the case studies, in: RISK MAP - Improving flood risk maps as a means to foster public participation and raising flood risk awareness: toward flood resilient communities, edited by: Meyer, V., Kuhlicke, C., Luther, J., Unnerstall, H., Fuchs, S., Priest, S., Pardoe, J., McCarthy, S., Dorner, W., Seidel, J., Serrhini, K., and Palka, G., 19-24, available at: http://risk-map.org/outcomes (last access: 2 March 2013), 2011.

Spachinger, K., Dorner, W., Metzka, R., Serrhini, K., and Fuchs, S.: Flood risk and flood hazard maps - Visualisation of hydrological risks, IOP Conf. Serie, Earth Environ. Sci., 4, 1-17, doi:10.1088/1755-1307/4/1/012043, 2008.

Steinführer, A., Kuhlicke, C., De Marchi, B., Scolobig, A., Tapsell, S., and Tunstall, S.: Towards flood risk management with the people at risk: from scientific analysis to practice recommendations (and back), in: Flood Risk Management: Research and Practice, edited by: Samuels, P., Huntington, S., Allsop, W., and Harrop, J., CRC Press/Balkema, Leiden, p. 167, 2009.

Swiss Re: Natural catastrophes and man-made disasters in 2011: historic losses surface from record earthquakes and floods, Sigma, 2, available at: http://media.swissre.com/documents/ sigma2_2012_en.pdf (last access: 6 September 2012), 2012.

Taylor-Gooby, P. and Zinn, J.: The current significance of risk, in: Risk in social science, edited by: Taylor-Gooby, P. and Zinn, J., Oxford University Press, New York, 2006.

Unnerstall, H.: Legal framework for public participation in flood risk mapping - A comparative study on different European member states and on the requirements of the Flood Management Directive, UFZ Discussion Paper 13/2010, Leipzig, 2010.

Wachinger, G., Renn, O., Begg, C., and Kuhlicke, C.: The risk perception paradox: implications for governance and communication of natural hazards, Risk Anal., doi:10.1111/j.15396924.2012.01942.x, online first, 2012.

Wagner, K.: Naturgefahrenbewusstsein und -kommunikation am Beispiel von Sturzfluten und Rutschungen in vier Gemeinden des bayerischen Alpenraums, Ph.D. Thesis, Studienfakultät Forstwissenschaft und Ressourcenmanagement, TU München, 2004.

Wagner, K.: Gefahrenkarten - Informationstool oder Stein des Anstoßes!?, in: Risikomanagement extremer hydrologischer Ereignisse: Beiträge zum Tag der Hydrologie 2006, edited by: Disse, M., Guckenberger, K., Pakosch S., Yörük, A., and Zimmermann A., Forum für Hydrologie und Wasserwirtschaftung, 15, 231-242, 2006.

Wagner, K.: Der Risikoansatz in der europäischen Hochwassermanagementrichtlinie Bewertung der Richtlinie 2007/60/EG über die Bewertung und das Management von Hochwasserrisiken aus 
politikwissenschaftlicher Sicht, Natur und Recht, 30, 774-779, doi:10.1007/s10357-008-1569-y, 2008.

Weichselgartner, J. and Sendzimir, J.: Resolving the paradox: food for thought on the wider dimensions of natural disasters, Mt. Res. Dev., 24, 4-9, 2004.

Werritty, A., Houston, D. M., Jobe, M., Ball, T., Tavendale, A. C. W. and Black, A. R.: The social impacts of flooding in Scotland: a national and local analysis, in: Flood risk management: research and practice, edited by: Samuels, P., Huntington, S., Allsop, W., and Harrop, J., CRC Press/Balkema, Leiden, 81, 2009.

WG, Wassergesetz für Baden-Württemberg vom 20. Januar 2005 (GB1. S. 219), available at: http://www.gaa.baden-wuerttemberg. de/servlet/is/16491/1_3_1.pdf (last access: 14 March 2013), 2005.
WHG, Wasserhaushaltsgesetz vom 31. Juli 2009 (BGB1. I S. 2585), das zuletzt durch Artikel 5 Absatz 9 des Gesetzes vom 24. Februar 2012 (BGB1. I S. 212) geändert worden ist, available at: http://www.gesetze-im-internet.de/bundesrecht/ whg_2009/gesamt.pdf (last access: 14 March 2013), 2009.

White, G. F., Kates, R. W., and Burton, I.: Knowing better and losing even more: the use of knowledge in hazards management, Environ. Hazards, 3, 81-92, 2001.

Wynne, B.: Public understanding of science, in: Handbook of science and technology studies, edited by: Jasanoff, S., Markle, G. E., Petersen, J. C., and Pinch, T., Sage Publications, Thousand Oaks, 361-388, 1995.

Yin, R. K.: Case study research: design and methods, 4th Edn., Sage Publications, Thousand Oaks, 2009. 